\title{
Scandal at Tokyo hospital
}

\section{Tokyo}

Following a tip-off from a newspaper, officials of Japan's Science and Technology Agency (STA) this week began digging up the grounds of the nation's leading university hospital looking for radioisotopic waste that may have been dumped illegally. The search is just one incident in a scandal at the Tokyo University hospital that has drawn attention to problems associated with the explosive growth in use of radioisotopes for research and medical purposes in Japan.

The scandal erupted two weeks ago when newspapers reported that an STA inspection of Tokyo University Hospital in November had revealed 30 serious defects in the handling of radioisotopes by the hospital, including failure to keep complete records of the use and disposal of radioisotopes, using radioisotopes in a research laboratory undergoing construction, using one-year's authorized supply of radioisotopes in six months and failure to supervise and educate researchers in the use of isotopes. The director of the hospital has publicly apologized and STA has banned the use of isotopes at the hospital for research purposes until the situation is rectified.

In addition to the mishandling pointed out by the agency, the Mainichi newspaper revealed that in dismantling a 20 year old betatron at the hospital last October, researchers were surprised to detect high levels of the dangerous isotope strontium-90. The strontium-90 dates from long-forgotten experiments carried out when the betatron was first built, according to Tetsuhiko Yoshida, director of STA's Radiation Protection Division.

The Mainichi also disclosed with photographs that on 7 November, just before the STA inspection, the hospital used part-time labourers to remove drums of radioisotope waste from the basement of the hospital without instructing them about the materials they were handling and without requiring them to wear film badges to determine their exposure to radiation.

This constitutes a violation of Japanese law, according to Yoshida. But the hospital has denied legal responsibility.

The decision to dig up the hospital grounds stems from another claim by the Mainichi that one of the hospital's own researchers told the newspaper that radioactive waste, including beakers and flasks, is buried there. In a preliminary survey last week, STA officials detected four 'hot spots' in the courtyard of the hospital with levels of radioactivity 10 to 100 times that of background.

There has been explosive growth in the number of organizations using radioisotopes for research in Japan over the past
30 years, and the amount of untreated (and partially treated) radioiosotope waste increased nearly sixfold beween 1980 and 1988 to more than 50,000 200-litre drums. But the Atomic Energy Commission is only just beginning to look into possible sites for waste disposal.

Yoshida thinks that the mishandling of radioisotopes at Tokyo University Hospital is a special case. Each year, the agency carries out safety checks at about 400 organizations that use radioisotopes for research purposes but none has shown such a large number of safety violations.

Yoshida sees three major causes for the problems at Tokyo University: the hospital building is old and poorly maintained, the number of technical staff trained in the safe use of radioisotopes is very limited and Tokyo University doctors have a high status in Japanese society and tend to ignore the advice of trained technicians.

David Swinbanks

\section{Brazil's pumps run dry}

\section{São Paulo}

BRAzIL's alcohol fuel programme, the largest alternative fuel programme in the world, is in dire straits. The supply of sugar-cane ethanol has failed to keep up with demand and, over the objection of environmentalists, the government is now coming up with a new 'cocktail' fuel that is part methanol, part ethanol and part gasoline. The alternative would be rationing of fuel for the four million Brazilians who own ethanol-driven cars.

Last week, environmentalists tried legal action to block emergency measures to add methanol to the sugar-cane alcohol 'gasohol'. They argue that methanol is highly toxic and that little is known of the emission from methanol-powered cars.

Legal action was not a success and the federal court reversed an earlier decision favouring prohibition of methanol. But the decision holds for only six months and cannot affect states and cities where the local executive or legislative have forbidden ethanol use. The decision calls for protection standards to be established by the Health Ministry and for a media campaign on the risks of the new 'cocktail' fuel. Besides being easier to ignite, the new fuel can pose an additional hazard to a well-established Brazilian habit siphoning fuel from tanks. The siphoners are both careless people who forget to fill their tanks and have to borrow from others, and less well-intentioned fuel thieves. Methanol ingestion can lead to blindness and death.

Researchers from the University of São Paulo have presented a report on the possible environmental effects of methanol use as has CETESP, the São Paulo state pollution control agency. Both groups advise that methanol use be coupled with monitoring of environmental effects and a campaign to inform the public of its risks.

CETESP officials are particularly angry with Brazilian environmentalists. Their opposition to the use of alcohol would mean more petrol use, and that would mean more carbon monoxide in the stifling air of major cities such as São Paulo and Rio de Janeiro. Ironically, these were among the first cities where local authorities banned methanol. But São Paulo's mayor, Luiza Erundinia, changed her mind last week and said she will permit methanol use, provided protection measures are taken.

Brazil's alcohol programme has been suffering from mismanagement and sheer bad luck. The country is the biggest sugarcane grower and the biggest producer of sugar and ethanol. And yet there is a serious shortage of alcohol.

Several factors are to blame. Instead of meeting government alcohol quotas, sugar-cane planters and distillery owners preferred to produce sugar and export it while prices were good.

Crops were not as large as expected. Government alcohol stocks were allowed to run down because of financial problems at Petrobras, the state oil company which buys alcohol from producers.

Consumption of alcohol has recently risen thanks to the short-lived success of the summer economic plan of 1989 , and industry is still geared up to produce more ethanol-powered cars than gasolinepowered ones, although that is changing. In 1985, sales of alcohol cars reached an all-time high of 96 per cent of the total; today it is down to 61 per cent. Brazil now has roughly a third of its 13 million vehicles running on alcohol.

Subsidies to sugar growers and distillers - a powerful lobby ever since colonial times - also distort fuel economics. Alcohol costs less to consumers than its real price, and gasoline costs more. Thanks to this policy, Petrobras has run up a huge deficit since the Proalcohol programme began in earnest in the $1980 \mathrm{~s}$.

Researchers have also come up with unexpected news about alcohol pollutant emissions. It is true that carbon monoxide and particulant levels are down. But alcohol fuels produce more aldehydes, which react in the atmosphere and create peroxyacetyl nitrate (PAN), a compound that stunts plant growth and causes eye irritation. Aldehydes also help increase ozone levels, one ingredient of smog.

Ricardo Bonalume Neto 